\title{
Rail Commuting Duration and Passenger Stress
}

\author{
Gary W. Evans \\ Cornell University
}

\author{
Richard E. Wener \\ Polytechnic University
}

Over 100 million Americans commute to work every weekday. Little is known, however, about how this aspect of work, which may indeed be the most stressful aspect of the job for some, affects human health and well-being. The authors studied a sample of 208 male and female suburban rail commuters who took the train to Manhattan, New York. The greater the duration of the commute, the larger the magnitude of salivary cortisol elevations in reference to resting baseline levels, the less the commuter's persistence on a task at the end of the commute, and the greater the levels of perceived stress. These effects were not moderated by gender. Commuting stress is an important and largely overlooked aspect of environmental health.

Keywords: commuting, trains, stress, cortisol, motivation

Over 100 million Americans commute to work each weekday. The duration of these trips has increased markedly over the past two decades because of a combination of greater commuting distances and elevated traffic congestion. Average daily commute times in the United States increased 18\% between 1980 and 2000, and workers commuting over an hour to their jobs represented the fastest growing category (Reschovsky, 2004). Although there is a large, well-developed literature on occupational stress and health, with a recent handbook on the field (Barling, Kelloway, \& Frone, 2005) and a scholarly journal largely devoted to the topic, Journal of Occupational Health Psychology, only a handful of studies have addressed stress in relation to commuting. Moreover, this research has focused on self-reports of stress symptoms among automobile commuters (Koslowsky, Kluger \& Reich, 1995; Stokols \& Novaco, 1981). In the current study, we examine multimethodological indicators of stress among rail passengers.

A few automobile commuter stress studies have supplemented self-reports of stress with physiological measures, revealing elevated cardiovascular outcomes (Bellet, Roman, \& Kostis, 1969; Robinson, 1991; Simonson et al., 1968; White \& Rotton, 1998). Singer, Lundberg, and Frankenhaeuser (1978), in the only train commuting study, found similar trends among rail passengers. White and Rotton (1998) extended these prior commuting studies

Gary W. Evans, Departments of Design and Environmental Analysis and of Human Development, Cornell University; Richard E. Wener, Department of Humanities and Social Sciences, Polytechnic University.

Partial support for this project came from the New Jersey Department of Transportation, the University Transportation Research Center-Region 2, and the Robert Wood Johnson Foundation. We are grateful to the rail passengers and their spouses who participated in this study. We thank Jerry Lutin, Robert Paaswell, Karl Brodtman, and Nick Vitello for their continued interest and support of this project and for the support of New Jersey Transit. Opinions stated herein are those of the authors and not necessarily those of the funders or any other agencies.

Correspondence concerning this article should be addressed to Gary W. Evans, Departments of Design and Environmental Analysis and of Human Development, Cornell University, Ithaca, NY 14853-4401. E-mail: gwe1@cornell.edu by showing evidence of motivational deficits in task performance using Glass and Singer's (1972) aftereffects paradigm. They found that student commuters compared with noncommuting controls (random assignment) had elevated blood pressure and poorer task persistence. A much larger number of studies have revealed that professional drivers, principally urban bus operators, also manifest elevated stress on the job (Evans, 1994; Evans \& Johansson, 1998). Additional studies have revealed that one of the major contributors to stress among drivers is exposure to traffic congestion. Feelings of frustration, irritation, and loss of control, along with elevated physiological stress and degraded task motivation, typically accompany driving under more congested conditions (Evans \& Carrere, 1991; Koslowsky et al., 1995; Novaco, Kliewer, \& Broquet, 1991; Novaco \& Sandeen, 1992; Novaco, Stokols, \& Milanesi, 1990; Schaeffer, Street, Singer \& Baum, 1988).

We build on these prior studies of stress and commuting among drivers by examining the role of commuting duration among suburban train commuters riding into Manhattan, New York. We hypothesized that the greater the duration of the commute, the more stressful the experience, as indicated by multimethodological indices of stress, including salivary cortisol, task motivation, and perceived stress. We expanded self-reports of stress to include spousal ratings, given prior work showing that spouses can reliably evaluate their partner's adverse reactions to stressful working conditions (Repetti, 1989).

\section{Method}

\section{Participants}

Two hundred eight rail commuters between the ages of 25 and 60 who rode from suburban New Jersey into Manhattan, New York were recruited through flyers and announcements handed out in New Jersey Transit stations for a study of the "commuting experience" conducted by Polytechnic University and Cornell University. Eligible participants commuted at least 3 days/week and had been on the same route for at least 12 months. Participants were paid for their participation with a monthly rail pass. Fifty-two percent of the participants were men, and $48 \%$ were women. The sample of men and women had a median income exceeding $\$ 95,000$. Seventy-nine percent of the commuters were college graduates. 


\section{Materials}

Salivary cortisol was collected with a Salivette (Sarstedt, Newton, North Carolina) in the train station at the end of the participant's morning trip to work and at the same time of day on the following weekend at the respondent's home. Samples were placed under $-20{ }^{\circ} \mathrm{C}$ until assay. Cortisol was analyzed by a time-resolved immunoassay with fluorescence detection (Dressendorfer, Kirschbaum, Rohde, Stahl, \& Strasburger, 1992). The difference between resting and on-task, or at-work, neuroendocrine hormones has been shown to be a reliable and valid marker of stress both in the laboratory and the field (Frankenhaeuser \& Johansson, 1986; Kirschbaum \& Hellhammer, 1989; Lundberg, 1984, 2000).

Motivation was measured near the end of the morning commute by persistence on a proofreading task (percentage errors detected). This measure has been widely used to assess aftereffects from stressor exposure both in the laboratory and the field (Cohen, 1980; Glass \& Singer, 1972).

Perceived commuting stress was assessed by the commuter during the commute to work on the train. Self-report of commuting stress was obtained using scales developed by Novaco and colleagues (Novaco et al., 1990, 1991; Novaco \& Sandeen, 1992) and Kluger (1998). Commuters indicated how stressful they found the commuting experience in general on nine 5-point Likert scales (e.g., "It takes a lot of effort to commute to work"; $\alpha=.90$ ).

The spousal rating form asked the participant's spouse or partner to evaluate the commuter's interpersonal interactions with the spouse or partner for that past week with 33 items from Repetti's (1989) Daily Marital Behavior Scale (e.g., "This week my partner took out his [her] frustrations on me"; $1=$ never; $5=$ once a day or more; $\alpha=.93$ ).

\section{Procedure}

Participants were mailed a packet prior to data collection that contained the informed consent procedure, instructions, and all of the above measures except for the Salivettes and spousal rating forms. All subject self-report data were collected on the train during the morning rush hour trip to work, except for spousal ratings. Commuting duration ranged from 45 to 180 min. Commuters were instructed to complete the questionnaire (background, ${ }^{1}$ commuting route and train information, commuting stress, and job stress) on the train once it left the station on the way to work. Commuters then self-administered the proofreading task beginning at a designated station stop near the end of the commute for a period of $10 \mathrm{~min}$. All commuters were then met as they disembarked from the train and a saliva sample was taken and the questionnaires collected.

The commuter's spouse or partner was asked to fill out his or her rating form at home on the weekend immediately following the on-the-train data collection. Baseline, salivary cortisol was also collected at the respondent's home that same weekend. The baseline saliva collection was carefully timed to match the time of day saliva had been collected on the train.

\section{Results}

Each of the four stress measures was regressed onto commuting time, statistically controlling for income, gender, ethnicity, and education level of the commuter. Commuting time was unrelated to conditions of the train car (e.g., density, having one's own seat, seat location) or the number of mode changes the commuter had to make on his or her commute. The difference score (commuting at home, nonworkday) was used to examine increases in physiological stress. The natural logarithm of cortisol was used given skewness in the data. This repeated measures general linear model approach is commonly used in field work with neuroendocrine hormones and in the present case yielded greater statistical power than a covariance analysis (commuting cortisol sample with week- end, at-home cortisol as covariate). The covariance analysis also yielded significant results. Descriptive statistics for raw data and zero-order correlations between the variables are included in Table 1 .

As suggested by Figures 1, 2, and 3, longer commutes were significantly associated with elevated cortisol (log of the commuting cortisol - $\log$ of the at-home baseline cortisol; $B=0.010, S E$ $=.003, p<.01)$; poorer proofreading performance $(B=-0.001$, $S E=.001, p<.07)$; and higher levels of perceived commuting stress $(B=0.007, S E=.002, p<.01)$. The figures depict the unadjusted means based on ordinary least-squares regression at the mean and one $S D$ above and below for commuting times. Spousal ratings of the commuter's stress, however, were unrelated to the duration of the commute $(B=0.002, S E=.003, n s)$. There were no statistical interactions of any sociodemographic background variables with commute duration on the outcome variables.

\section{Discussion}

Prior studies have revealed that automobile commuting is stressful, as indicated by self-reports of stress and physiological indicators (Koslowsky et al., 1995; Novaco et al., 1990, 1991; Novaco \& Sandeen, 1992; Schaeffer et al., 1988). In the current study, we show that these effects also appear to occur among rail commuters, with those facing longer trips suffering more stress. As shown in Figures 1, 2, and 3, these impacts are robust, manifesting in self-report, task persistence, and salivary cortisol.

The present data are also important to consider within the context of public policy as typical commuting times continue to expand dramatically in America (Reschovsky, 2004). In addition to obvious detrimental ecological impacts, longer commutes are related to stress and could very well interfere with active lifestyles, given the decreased availability of time to exercise and longer periods away from home (Frumkin, Frank \& Jackson, 2004). Thus, the present data provide additional support for advocates of smart growth who argue that community planning needs to emphasize greater pedestrian access to local recreational and retail activities (Benfield, Terris, \& Vorsanger, 2001).

The present results are interesting in at least three other respects. First, we uncovered a linear, dose-response function between the duration of the commute and multiple stress outcomes. The relation between commute duration, at least over the range of 45-180 min, and stress is linear. We checked for nonlinearity in the data, and none was found.

Second, our data are consistent with an intervention study in which improved service that eliminated train changes and reduced commuting time significantly lowered stress levels in rail commuters (Wener, Evans, Phillips \& Nadler, 2003). The present study and prior studies of automobile commuting reflect the potential contributions of the physical environment to human stress and health. We already know that crowding, noise, and poor housing quality can affect psychological stress (Evans, 2001; Halpern, 1995). Commuting conditions need to be added to the rubric of environmental stressors. Research on commuting also expands our conceptualization of occupational conditions and health. Commut-

\footnotetext{
${ }^{1}$ Unfortunately age was inadvertently omitted from the background questionnaire.
} 
Table 1

Study Descriptive Statistics and Zero-Order Correlations Between Variables

\begin{tabular}{|c|c|c|c|c|c|c|c|c|c|c|c|}
\hline Variable & $M$ & $S D$ & 1 & 2 & 3 & 4 & 5 & 6 & 7 & 8 & 9 \\
\hline 1. Commute time (min) & 81.65 & 23.06 & - & $.19 *$ & -.05 & $.20^{* *}$ & -.10 & -.06 & -.11 & -.07 & .01 \\
\hline 2. Baseline cortisol (nmol/l) & 4.92 & 5.41 & & - & $.36^{* *}$ & .05 & -.04 & $-.14 *$ & .06 & -.12 & -.12 \\
\hline 3. Commuting cortisol (nmol/1) & 5.62 & 5.54 & & & - & -.05 & -.11 & $-.14 *$ & .07 & -.06 & .02 \\
\hline 4. Perceived commuting stress ${ }^{\mathrm{a}}$ & 3.19 & 0.68 & & & & - & $-.17^{*}$ & .14 & $.15^{*}$ & .05 & .05 \\
\hline 5. Proofreading ( $\%$ errors detected) & 56 & 18 & & & & & - & $.17 *$ & $.18 *$ & .09 & $.35^{* *}$ \\
\hline 6. Education level ${ }^{\text {b }}$ & 5.71 & 1.23 & & & & & & - & $-.14 *$ & $.28 * *$ & .05 \\
\hline 7. Gender ${ }^{\mathrm{c}}$ & & & & & & & & & - & .06 & -.10 \\
\hline 8. Income $^{\mathrm{d}}$ & 7.41 & 2.24 & & & & & & & & - & .01 \\
\hline 9. Ethnicity ${ }^{\mathrm{e}}$ & & & & & & & & & & & - \\
\hline
\end{tabular}

${ }^{\mathrm{a}} 1=$ low; $5=$ high stress. $\quad{ }^{\mathrm{b}} 1=$ some high school; $7=$ advanced degree. $\quad{ }^{\mathrm{c}} 2=$ male; $52 \%$ men; $48 \%$ women. $\quad{ }^{\mathrm{d}} 1=\$ 15-25 \mathrm{~K} ; 9=>\$ 95 \mathrm{~K} . \quad{ }^{\mathrm{e}} 0=$ non-White; 77\% White; 33\% non-White (African American, Asian American, Hispanic, and other).

$* p<.05$. $* * p<.01$.

ing conditions constitute an important component of the work setting that may contribute to health and well-being.

Third, the present results highlight the critical importance of time in research on environment, health, and behavior. There is a strong paradigmatic thrust in environmental health research to focus on the intensity of environmental exposures without sufficient attention to the duration of exposure. Levels of toxins, pollutants, noise, crowding, and the like are nearly always the focus of inquiry. Yet, how long one must contend with suboptimal environmental conditions may be just as important as the level of environmental quality when considering health effects.

Some limitations of the present study should be noted. Spousal ratings of commuter stress, unlike the other three multimethodological indices of stress, did not converge. A second limitation of the study is the sample. As indicated in the Method section, our sample is wealthy and highly educated. Although our sample is representative of rail commuters from New Jersey suburbs into midtown Manhattan, it is obviously not a good representation of commuters in general. We did check for gender interactions with commute duration and found none. It is also worth briefly mentioning that Wener et al. (2003), in their intervention study, found

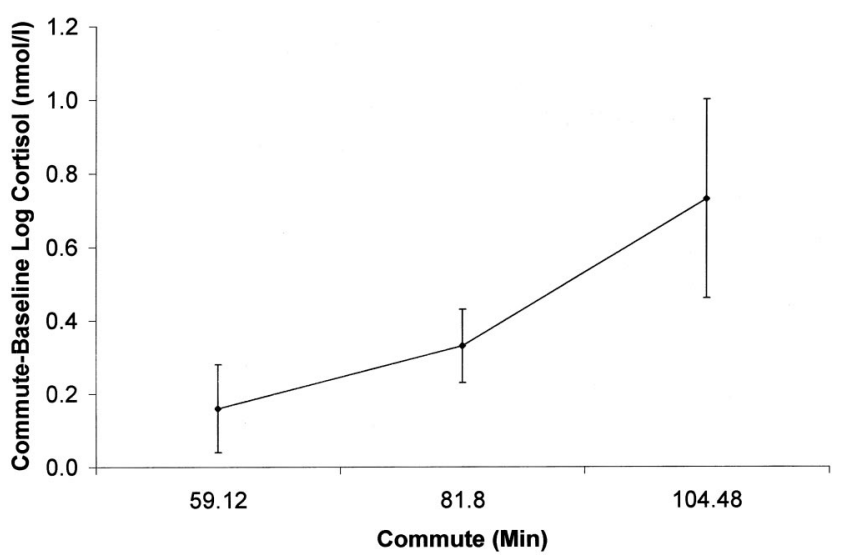

Figure 1. Physiological stress (commute - baseline log of salivary cortisol) in relation to commuting time to work. Unadjusted means and standard errors (represented by error bars) are shown at the mean and one standard deviation above and below for commuting times to work. very similar effects of improved service in actual rail commuters and in an experimental simulation using college students. There is also widespread cross-cultural evidence of similar, adverse commuting effects among bus drivers (Evans, 1994; Evans \& Johansson, 1998). We restricted subject recruitment to adults between the ages of 25 and 60 but did not record each participant's age, precluding use of this variable as an additional covariate. Although the restricted age range and the use of income as a covariate in our analyses make it unlikely that commuting duration effects could be attributable to age or seniority, it would have been preferable to examine the potential role of age more directly.

Other temporal dimensions that may impact commuting stress were not assessed directly in our study. We had an eligibility criterion of 12 months minimum on the same commute, but variation in commuting histories could moderate the impacts of the trip length uncovered herein. It is also possible that longer commutes are associated with greater time urgency or time pressure. We did not assess time urgency as a potential mediator of the relation between commuting duration and stress. Furthermore, psychological factors such as Type A coronary prone behavior, job satisfac-

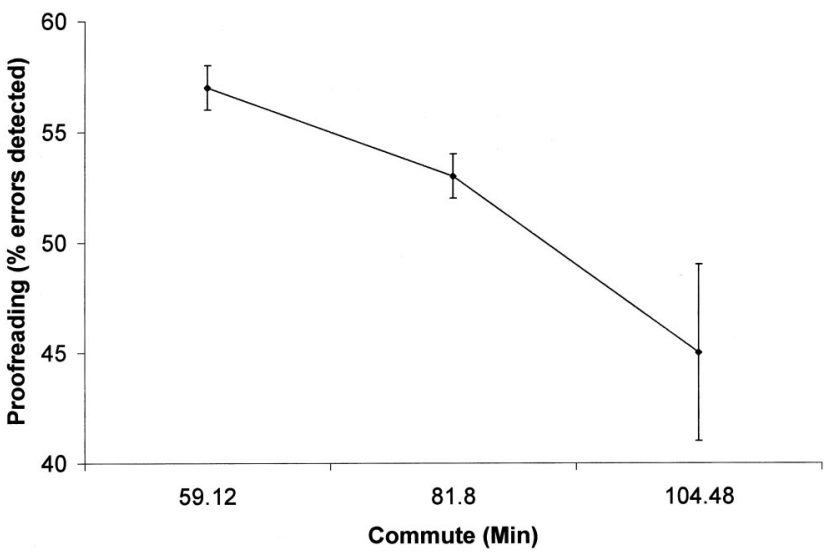

Figure 2. Motivation in relation to commuting time to work as indexed by proofreading performance (\% errors detected in a prose passage). Unadjusted means and standard errors (represented by error bars) are shown at the mean and one standard deviation above and below for commuting times to work. 


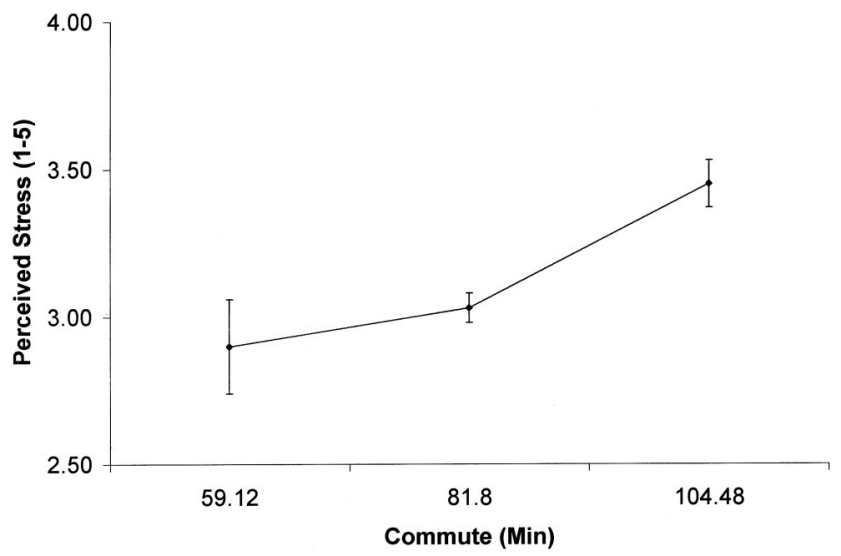

Figure 3. Perceived commuting stress in relation to commuting time to work. Higher scores on this standardized scale indicate greater selfreported stress. Unadjusted means and standard errors (represented by error bars) are shown at the mean and one standard deviation above and below for commuting times to work.

tion levels, and perceptions of choice and control over residential location have been shown to moderate commuting stress among automobile commuters (Koslowsky et al., 1995; Stokols \& Novaco, 1981). Future work on stress from train commuting plus other forms of mass transit use ought to incorporate these and other psychological factors as potential moderator variables.

Although we statistically controlled for income, education, gender, and ethnicity, the study design is cross-sectional. Thus, some other variable, unrelated to any of these sociodemographic background factors, could be driving our findings. We can rule out conditions of the train car itself as well as number of mode changes during the commute because these were unrelated to commuting duration, but stronger evidence would follow from a longitudinal study of changes in commuting times.

We matched cortisol sampling times on the morning of the commute to work with a nonworkday, morning sample. However, some people sleep later on weekends, which means that matching the sample time may cause variability in the interval between awakening and saliva collection. Unfortunately, we did not record awakening times on the work or weekend, off-work day. Increases in awakening time on weekends compared with workdays among working adults are negatively correlated with morning cortisol levels (Schlotz, Hellhammer, Schulz, \& Stone, 2004). Thus, it is possible that some of the effects we attribute to commuting duration are due to delayed awakening times. We believe this is unlikely, however, because Schlotz et al. (2004) also found that (a) the effects of work stress on morning cortisol levels were independent of weekend-weekday differences in awakening times and (b) morning cortisol correlates of awakening time difference between workday and weekend day were caused by work stress levels and not inherent to time of awakening.

In addition to strengthening the design of our study and broadening the background characteristics of the sample, another topic warranting further investigation would be the examination of underlying psychological processes that might account for the adverse impacts of commuting. Are longer commutes more stressful simply because of effort and fatigue or do control and predictabil- ity also matter? Longer commutes to work may also elevate time pressure. Other health and behavioral outcomes of commuting duration could also be investigated. For example, how is worker productivity influenced by commuting time? Over an extended period of time, does commuting duration affect morbidity? Obviously, not all commuters respond in the same manner to the daily grind of commuting. Are there effective coping strategies that enhance resilience to commuting stress?

Commuting is a ubiquitous stressor for millions of people. Yet, this environmental condition has largely been ignored in theoretical and empirical work on occupational stress and health. For some workers, commuting may indeed be the most stressful aspect of their job. Prior work has documented some of the psychological and physical health costs of commuting to work by car, especially under heavy traffic conditions. We have shown that the duration of rail commuting may also be a salient stressor for many working people.

\section{References}

Barling, J., Kelloway, K., \& Frone, M. (2005). Handbook of occupational stress. Los Angeles: Sage.

Bellet, S., Roman, L., \& Kostis, J. (1969). The effects of automobile driving on catecholamine and adrenocortical excretion. American Journal of Cardiology, 24, 365-368.

Benfield, F. K., Terris, J., \& Vorsanger, N. (2001). Solving sprawl. Washington, DC: Island Press.

Cohen, S. (1980). Aftereffects of stress on human performance and social behavior. Psychological Bulletin, 88, 82-108.

Dressendorfer, R. A., Kirschbaum, C., Rohde, W., Stahl, F., \& Strasburger, C. J. (1992). Synthesis of a cortisol-biotin conjugate and evaluation as a tracer in immunoassay for salivary cortisol. Journal of Steroid Biochemistry and Molecular Biology, 43, 683-692.

Evans, G. W. (1994). Working on the hot seat: Urban bus operators. Accident Analysis and Prevention, 26, 181-193.

Evans, G. W. (2001). Environmental stress and health. In A. Baum, T. Revenson, \& J. E. Singer (Eds.), Handbook of health psychology (pp. 365-385). Mahwah, NJ: Erlbaum.

Evans, G. W., \& Carrere, S. (1991). Traffic congestion, perceived control, and psychophysiological stress among urban bus drivers. Journal of Applied Psychology, 76, 658-663.

Evans, G. W., \& Johansson, G. (1998). Urban bus driving: An international arena for the study of occupational health psychology. Journal of Occupational Health Psychology, 3, 99-108.

Frankenhaeuser, M., \& Johansson, G. (1986). Stress at work: Psychobiological and psychological aspects. International Review of Applied Psychology, 35, 287-299.

Frumkin, H., Frank, L., \& Jackson, R. (2004). Urban sprawl and public health. Washington, DC: Island Press.

Glass, D. C., \& Singer, J. E. (1972). Urban stress. New York: Academic.

Halpern, D. (1995). Mental health and the built environment. London: Taylor \& Francis.

Kirschbaum, C., \& Hellhammer, D. (1989). Salivary cortisol in psychobiological research. Neurobiology, 22, 150-169.

Kluger, A. (1998). Commute predictability and strain. Journal of Organizational Behavior, 19, 147-165.

Koslowsky, M., Kluger, A., \& Reich, M. (1995). Commuting stress. New York: Plenum Press.

Lundberg, U. (1984). Human psychobiology in Scandinavia: Psychoneuroendocrinology-human stress and coping processes. Scandinavian Journal of Psychology, 25, 214-226.

Lundberg, U. (2000). Catecholamines. In G. Fink (Ed.), Encyclopedia of stress (Vol. 1, pp. 408-413). New York: Academic Press. 
Novaco, R. W., Kliewer, W., \& Broquet, A. (1991). Home environmental consequences of commute travel impedance. American Journal of Community Psychology, 19, 881-909.

Novaco, R. W., \& Sandeen, B. (1992). Mitigating the stress of commuting to work: Ridesharing and the interaction effects of gender. In APA/ NIOSH Conference on Stress in the 90s: A changing workplace in a changing world. Washington, DC: American Psychological Association.

Novaco, R. W., Stokols, D., \& Milanesi, L. (1990). Objective and subjective dimensions of travel impedance as determinants of commuting stress. American Journal of Community Psychology, 18, 231-257.

Repetti, R. (1989). Effects of daily workload on subsequent behavior during marital interaction. Journal of Personality and Social Psychology, 57, 651-659.

Reschovsky, C. (2004). Journey to work: 2000. Census 2000 Brief. Retrieved January 9, 2006, from http://www.census.gov/prod/2004pubs/ c2kbr-33.pdf

Robinson, A. (1991). Lung cancer, the motor vehicle, and its subtle influence on bodily functions. Medical Hypotheses, 28, 39-43.

Schaeffer, M., Street, S., Singer, J. E., \& Baum, A. (1988). Effects of control on the stress reactions of commuters. Journal of Applied Social Psychology, 11, 944-957.

Schlotz, W., Hellhammer, J., Schulz, P., \& Stone, A. A. (2004). Perceived work overload and chronic worrying predict weekend-weekday differences in the cortisol awakening response. Psychosomatic Medicine, 66, 207-214.

Simonson, E., Baker, C., Burns, N., Keiper, C., Schmitt, O., \& Stackhouse, S. (1968). Cardiovascular stress (electrocardiographic changes) produced by driving an automobile. Fundamental of Clinical Cardiology, $75,125-135$.

Singer, J. E., Lundberg, U., \& Frankenhaeuser, M. (1978). Stress on the train: A study of urban commuting. In A. Baum, J. E. Singer, \& S. Valins (Eds.), Advances in environmental psychology (Vol. 1, pp. 41-56). Hillsdale, NJ: Erlbaum.

Stokols, D., \& Novaco, R. W. (1981). Transportation and well being. In I. Altman, J. F. Wohlwill, \& P. Everett (Eds.), Transportation and behavior (pp. 85-130). New York: Plenum Press.

Wener, R. E., Evans, G. W., Phillips, D., \& Nadler, N. (2003). Running for the 7:45: The effects of public transit on commuter stress. Transportation, 30, 203-220.

White, S., \& Rotton, J. (1998). Type of commute, behavioral aftereffects, cardiovascular activity. Environment and Behavior, 30, 763-780.EQ1: Received, Revised, Accepted lines missing—dates on ms. transmittal form. 